Kroneman, M.W., Zee, J. van der. Health policy as a fuzzy concept: methodological problems encountered when evaluating health policy reforms in an international perspective. Health Policy: 1997, 40(2), 139-155

\begin{tabular}{|l|l|}
\hline $\begin{array}{l}\text { Postprint } \\
\text { Version } \\
\text { Journal website }\end{array}$ & 1.0 \\
\hline Pubmed link & $\underline{\text { http://www.journals.elsevierhealth.com/periodicals/heap/article/S0168- }}$ \\
\hline DOI & $\underline{\text { http://www.ncbi.nlm.nih.gov/pubmed/10167068 }}$ \\
\hline \multicolumn{2}{|l|}{ This is a NIVEL certified Post Print, more info at http://www.nivel.eu } \\
\hline
\end{tabular}

\title{
Health policy as a fuzzy concept: Methodological problems encountered when evaluating health policy reforms in an international perspective
}

\author{
MADELON W. KRONEMAN ${ }^{\mathrm{A}},{ }^{*}$, JOUKE VAN DER ZEE $^{\mathrm{B}}$ \\ ${ }^{a}$ NIVEL, University of Utrecht, P.O. Box 1568, 3500 B.N. Utrecht, The Netherlands \\ ${ }^{\mathrm{b}}$ NIVEL, Maastricht University, Maastricht, The Netherlands \\ * Corresponding author. Tel.: + 3130 2319946; fax + 3130 2319290; e-mail: \\ j.vanderzee@niveI.nl
}

\begin{abstract}
Investigating health policy reforms at a national level is a troublesome task, since it is difficult to establish exactly when a certain policy change took place and it is also difficult to determine the content of the reform. In this paper three main causes are distinguished that contribute to the 'fuzziness' surrounding reforms. Firstly, ordinary mistakes occur, even experts err. Secondly, in some countries responsibility for (part of the) health care system is delegated to the regional level, causing regional variations which lead to uninterpretable effects at country-level health care system descriptions. Thirdly policy reforms are often not a straightforward process. Implementations can be characterized as a gradual process which can be disturbed at any point in time. For example, the use of framework legislation, effects of public discussions and law enforcement problems contribute to the fuzziness. To strengthen the validity of information from secondary sources (often the best available and linguistically accessible sources) the use of primary sources and expert consultation highly recommended, respectively giving insight in formal rules and initial intentions of policy measures and in the impact of reforms at performance level. The fuzziness can be captured into an index (reform implementation index), containing the gathered information and thus facilitating statistical analyses controlling for process-information. 01997 Elsevier Science Ireland Ltd.
\end{abstract}

\section{INTRODUCTION}

The steady expansion and improving quality of the OECD health database files simplifies international comparative health studies and makes them more attractive to use. The international health data file has become a popular research tool through the desire to connect the wave of health care reforms undertaken throughout the industrialized world to the OECD time series to establish their effect [1-10]. However, making connections between 
Kroneman, M.W., Zee, J. van der. Health policy as a fuzzy concept: methodological problems encountered when evaluating health policy reforms in an international perspective. Health Policy: 1997, 40(2), 139-155

a data file and health reforms is not without problems, as the authors of this paper discovered during their international comparison of the relationships between hospital utilization, planning and budgeting. Sources contradicted each other, or were insufficiently specific, and even official documents were not always decisive about the exact time schedule of the reforms. Apparently 'health policy' is a rather 'fuzzy' concept. In the first part of this paper a set of possible causes of this 'fuzziness' is described; in the second part possible solutions to deal with the fuzziness are discussed.

\section{CAUSES OF FUZZINESS}

The reasons why it is difficult to establish exactly when a certain policy change took place can be divided into three categories.

The first is the most simple: ordinary mistakes or misunderstandings; even experts err.

The second applies to the relevance of the national level and of national data to the analysis of health care policy developments; in some countries the regional level is more appropriate.

The third regards the introduction of a deliberate vagueness in policy making, resulting in an emphasis on the process rather than the content of policy making.

\subsection{Mistakes, errors and misunderstandings}

The first category of causes of obscurities evolves from simple mistakes or misunderstandings which are sometimes reinforced by uncritical copying of sources.

An example was found in Rosa and Launois' description of the French health care system published in 1990 [11]. They characterize the hospital payment system in France as a per diem system, although in the mid eighties the per diem system was replaced by a global budget system.

An example of an unavoidable cause of discrepant dates is what may be called the ' 31 st December effect'. A parliament may ratify a reform in the month of December and put into effect some months later, in the following year. As a result, both dates are found in the literature in connection with the reform. An example is the German KrankenhausKostendampfungsgesetz (Hospital Cost Containment Act) of December 1981 [12].

\subsection{Regionalization}

A second type of source leading to problems in finding out what is going on in a country lies in the implicit assumption that there is a national health care system and a national health care policy. However, there is an increasing trend to delegate responsibilities to regional levels. These responsibilities may include main line health policy issues. An example of this can be found in Switzerland, where each canton is responsible for its own health care system. Another example is found in the US, where part of the health care system is regulated at the national level (Medicaid and Medicare), while other parts are left to state level. Delegation of responsibility to lower level authorities was also found in Germany. Here, the planning and financing of hospital investments is now the responsibility of the Bundeslander; the Federal state is no longer responsible. In Sweden, the hospital financing system is regulated by the counties, where DRG style financing systems as well as block contracts are to be found [13]. The national level is evidently not the right analysis unit for evaluating health care reforms; the regional level should be used.

\subsection{Vaguely defined national policies}

The next type of obscurity source stems from the nature of most major reforms.This is where the 'fuzziness' comes in. The implementation of a reform is often not a straightforward process with clear changes evident from one day to the next. Implementation 
Kroneman, M.W., Zee, J. van der. Health policy as a fuzzy concept: methodological problems encountered when evaluating health policy reforms in an international perspective. Health Policy: 1997, 40(2), 139-155

can better be characterized as a gradual process, a process which can be disturbed at any point between implementation and enforcement.

\subsubsection{Phasing and adapting}

Complex and drastic reforms are often introduced step by step, mostly with the objective of avoiding the confrontation of health care providers with sudden changes in their financial resources. An example can be found in Hungary with the introduction of the DRG system for hospital reimbursement. The new administrative system was introduced in 1992. But, in that year, the system was only used to register output. The amount of money the hospitals received was still based on the old system; in casu number of beds. In 1993, hospitals were recompensed according to the new system. Deviations in budgets were compensated for according to the previous budget, to avoid hospitals having to face large deviations from their customary turnover. Now, in 1996, these corrections are still in operation. So, in practice, the new financing system has not yet been put into effect, since the financial consequences are yet to be rigorously applied.

In France, too, there appears to have been a gradual introduction of the global budget system. It is not, however, clear from the literature the extent to which the budget system was introduced in each year. The earliest date mentioned is 1983 [14,15], the last date referred to is 1986. One publication alluded to January 1986 [4]. Such a detailed date might lead one to believe that this was the correct date. Unfortunately, a second publication [16], gave January 1985 as the date on which the system was introduced. A second reasonable assumption might be that French authors were better informed and more able to give reliable information than foreign authors. However, French authors seem to be even less conclusive about the exact date of introduction than their foreign counterparts, as can be seen from Fig.1. Some references suggest a gradual introduction. The OECD report on health reforms ([4], pp. 50) and Aiach and Delanoe ([17], pp. 544) for instance state that the budget system came into effect in 1984 for larger hospitals and in 1985 for the remainder. According to Aiach and Delanoe, the law was passed by parliament in 1983 [17]. One is led to deduce that there must have been a gradual implementation of the global budget system.

In the Netherlands, the basis of reforms is currently formulated in policy documents outlining the direction of the reform. Implementation is planned step by step. An example is the 'Dekker Plan', published in 1987. This plan aimed to abolish the distinction between the public and private insurance systems by introducing statutory insurance for everyone. However, successive government changes led to the plan being amended and it may now never be implemented completely. This kind of process can lead to misunderstandings concerning the state of implementation. In his book on health insurance, Glaser writes that 'every Dutch citizen is now required to enrol under statutory health insurance' ([18], pp. 61). His informants during his visits in 1986 and 1987 were apparently convinced that this plan would eventually be carried out. Time, however, has decided differently.

\section{[FIGURE 1]}

\subsubsection{Increasing use of 'framework legislation'}

Another type of obscurity source arises from the use of framework legislation. Framework laws contain only major principles; further implementation is effected by inconspicuous ministerial or royal decrees. An example is the Dutch Health Facility Act on the planning of health services. (The 'Wet voorzieningen gezondheidszorg'). Parliament passed this law in 1982, but, apart from some small experiments and one decree regulating the establishment policy for General Practitioners, the law was never properly implemented. So, in formal 
Kroneman, M.W., Zee, J. van der. Health policy as a fuzzy concept: methodological problems encountered when evaluating health policy reforms in an international perspective. Health Policy: 1997, 40(2), 139-155

terms, there has been a health care services planning law in existence since 1982, but in practice the situation has not changed. However, Meyer-Lie [19], in his comparative health services study published in 1986, describes the Health Facility Act as actually having been implemented completely, his sources being official documents and two visits [19].

\subsubsection{The foreshadow of the future}

The next phenomenon can be characterized as 'foreshadowing the future' and has previously been described by Groenewegen [20]. As a result of discussions of future reforms in politics, the parties concerned try to maintain control by anticipating forthcoming changes [20]. Again, a clear example can be found in the Netherlands. As a result of the public debate concerning compulsory basic insurance for all Dutch citizens together with voluntary additional insurance in which health care insurers (both private and public) were to be obliged to compete, public and private health insurance funds gave urgent attention to a large scale merge which would strengthen their market position and limit competition. So, in place of the 53 public health insurers and 82 private health insurance companies of 1986, we now find, 8 years later, some 80 health insurers, most of a mixed public/private character. The proposed changes in the compulsory insurance system have, however, been postponed and at this moment it is not clear whether they will ever be introduced. In Sweden a similar foreshadow of the future was also experienced with the introduction of a guaranteed limited waiting time of not more than three months for certain surgical procedures. The waiting lists shortened during the period while the guarantee was still under discussion and this reduction continued into the period between the proposal being put before parliament and being put into effect [21].

\subsubsection{Deliberate vagueness in order to create broad support or in other words: governing} by magic and managing by speech

Governments are sometimes deliberately vague in order to gain broad political support. An example of such an approach is Germany's Concerted Action in Health Care (Konzertierte Aktion im Gesundheitswesen). 'Concerted Action' is a committee consisting of representatives from all sectors of health care. The decision making process is based on consensus. No sanctions are imposed for failing to arrive at recommendations, nor (when they are) for failing to implement them [4,12,22-24]. This kind of consultative structure derives its effectiveness from the threat of government intervention in the case of no consensus being reached [25]. It is, however, far from easy for a researcher to discover exactly what has been decided upon and to what extent it is put into effect.

\subsubsection{Law enforcement problems}

Another phenomenon that can cause deviations from the formal date of implementation of a reform evolves from low public support of a policy measure and weak incentives to enforce the law. These factors may result in disregard of the measure to be implemented. An example of this is hospital planning policy in Belgium. The first law concerning hospital bed planning dates from 1963. In 1973 and 1982, more restrictive measures were introduced. Hospital beds seemed, however, to evolve autonomously, independently of any policy measure [26-28]. Hospitals found creative solutions to the limitations, such as having more than $100 \%$ occupancy rate of legal beds to cover the 'black' beds (beds indicated as superfluous). This was possible because of the per patient settlement of hospital days. So, on paper, hospital planning in Belgium has been regulated since 1963, but in practice the measures had no effect at all until 1982 [26].

In short, there appear to be three major problems that can be encountered in investigating what has happened in the case of health care reforms. The first problem is inherent in the use 
Kroneman, M.W., Zee, J. van der. Health policy as a fuzzy concept: methodological problems encountered when evaluating health policy reforms in an international perspective. Health Policy: 1997, 40(2), 139-155

of secondary or tertiary sources. These sources often only describe main characteristics and give detailed information only where this is relevant for the writer's subject matter. The effect is that information sources which are incomplete can seem to contradict each other.

The second problem addresses the appropriateness of the national level. The national level is not always meaningful when studying health care systems. It appears to be more and more the case that responsibilities are delegated from the national level to regional levels.

The third problem, vaguely defined national policies, derives from the nature of many reforms. Reforms are often introduced gradually, so that no clear starting point can be distinguished. Another problem is that the formal date of implementation does not always indicate the commencement of the reform. Sometimes preliminary public debate leads to anticipatory behaviour by the actors concerned; sometimes incentives are not strong enough to persuade the actors to observe the reform.

\section{HOW TO DEAL WITH THE FUZZINESS}

Above, some explanations for the fuzziness of health policy reform information have been given. The question which then arises is which approaches should be applied to attain an optimum reliable insight into what has actually happened, and to what extent do these approaches lead to satisfying results. The problem remains of adapting this information for statistical analysis. Essentially, the central point is how to deal with problems of inconsistencies and gradual implementation. In this section, methods of accommodating the problems are presented. The examples given for each method illustrate the extra value added in comparison with the other methods.

\subsection{Gathering reliable information}

\subsubsection{The use of secondary sources}

Secondary sources are often global in nature; they provide a global insight into what has changed in a country with respect to health care reforms. This kind of information is readily available and is often linguistically accessible. Secondary sources provide very suitable starting points for studying health care reforms. Not only do they contribute global insights; they also facilitate determination of a point where further investigation is necessary, because inconsistencies have been discovered, or because information is incomplete, or is insufficiently specific. It is important to evaluate these sources critically, because personal interpretations are inevitable when authors have to summarize or select information. Choices may lead to biased information and different interpretations can lead to apparent contradictions.

\subsubsection{The use of primary sources}

Discovering the initial intention of a reform may require the consultation of primary sources. Legal texts reveal the official regulation and exact figures concerning budget ceilings, norms (for example, the number of beds per population), and so forth. The use of primary sources, however, requires knowledge of the language of the country. This can be a problem; while English, German and French are accessible, languages such as Hungarian or Swedish are not (at least, not to the authors of this paper). Using primary sources alone brings with it the drawback indicated above that regulations are not always completely 
Kroneman, M.W., Zee, J. van der. Health policy as a fuzzy concept: methodological problems encountered when evaluating health policy reforms in an international perspective. Health Policy: 1997, 40(2), 139-155

enforced, or may display unintended side effects. Such supplementary information may be missed if only primary sources are relied upon.

\subsubsection{Consultation of experts}

The second procedure concerns the inconsistencies and omissions in secondary and tertiary literature. A comprehensive literature search can form the basis of an overview of the reform. The overview, together with questions referring to any omissions or inconsistencies identified, can be put to experts within the countries concerned. Confinement to a single source, or to spokesmen from just one sector, is risky. Consulting representatives of the different sectors-the legislative body, the supply of care, health care insurance-is far more productive. Someone with practical experience (a hospital manager, for example) should also be included. The information thereby accumulated should enable the construction of a most probable reproduction of the reform process. It is, however, necessary to bear in mind that this reconstruction may still contain errors.

\subsection{To adapt the information to suit statistical analysis}

Even when the content and implementation procedures of the policy measure are clear, this reconstruction is still not straightforwardly appropriate for the (statistical) analysis of the effect of the measure. The following procedure is proposed to remedy this problem.

\subsubsection{Development of a 'reform implementation index'}

This index provides knowledge of the extent to which a reform has been implemented for the years preceding and following the implementation. The index is expressed as a value between 0 and 1. In Fig. 2, two examples of such an index are given. The upper diagram illustrates a reform that elicited reactions from the field, even before the formal introduction. The reform was spread gradually all over the country before it finally came into effect. The second picture illustrates phase by phase implementation; in this example full implementation was never reached. In this way, for each point in time (in our example, each year), the extent to which the reform has been effected can be expressed (on a scale from 0 to $1)$.

\section{[FIGURE 2]}

\section{PRACTICAL EXPERIENCES WITH THE PROPOSED METHODS}

In the following examples the added value and drawbacks of the proposed methods are outlined and illustrated by means of examples. The extra value from a comprehensive study of primary sources compared with the information obtained from secondary sources is illustrated by the development of the hospital law in Belgium. The effect of additional expert consultation is illustrated by a reconstruction of the implementation of the new hospital budgeting system in Hungary. The usefulness of the reform implementation index was tested on the implementation of the global budgeting system in France.

\subsection{Secondary sources versus primary sources}

What is the extra value obtained from a comprehensive study of primary sources compared with the information obtained from other sources? To answer this question, a case study of 
Kroneman, M.W., Zee, J. van der. Health policy as a fuzzy concept: methodological problems encountered when evaluating health policy reforms in an international perspective. Health Policy: 1997, 40(2), 139-155

the hospital planning reforms in Belgium was carried out. Belgium was chosen because, while from the authors' perspective the Belgian system is foreign, the primary sources are readily accessible, since they are in Dutch.

What is the advantage of using primary sources? For Belgium, all the ministerial and royal decrees were listed, with their content and official implementation date. Also, information giving exact figures of norms for hospital bed planning and computation rules for the hospital budget were described in detail. In the secondary sources, this kind of information was lacking. Also, in the secondary literature, the exact dates and content of ministerial decrees was not always clear, while this information was readily available in the primary sources. But, as we have noted, a major drawback of primary sources is that the actual implementation can differ markedly from the formal situation.

\subsection{The result of expert consultation in Hungary}

In Hungary, the hospital financing system changed from a system based on historical budgets (based largely on the number of beds and negotiation skills of the hospital manager) to an output based system, by means of DRGs. In the written sources, there was some imprecision about the implementation date. Further, a gradual adaptation from the historical budget to the new system was reported. To discover the exact date of implementation and the actual course of the adaptations, three different experts were consulted; a hospital manager, the head of the administrative department that carried out the financial administration of the DRGs, and an executive of the health insurance fund. They were also asked to comment on the actual operation of the new financing system. These interviews afforded an excellent insight into the working of the system. It appeared that the proposed gradual adaptation in practice was yet to start; budgets were still based on historical budgets. There also appeared to be a major control problem; there was no check between the patient's actual illness and declared illness. Hospitals were therefore motivated to represent the patient's illness as seriously as possible.

\subsection{The application of the 'reform implementation index' in France}

The example we take is the effect of introducing a global budget system into hospital utilization in France. Hospital utilization is operationalized as average length of stay and hospital turnover rate. The average length of stay and turnover rate show, respectively, autonomous decreasing and increasing trends over time, as can be seen in Fig. 3. The hypothesis tested is that the implementation of the reform caused a deviation in these trends: both the decrease in the average length of stay and the increase in the turnover rate became more marked. A regression equation was therefore fitted in which 'year' was included to facilitate estimation of the autonomous trend.

The question which arises is how to include the reform into the analysis. Here, three models are tested. For the first modei it is assumed that the reform has been in effect since its formal introduction in 1983. An index is developed with the value 0 (zero) before 1983 and the value 1 (one) after 1983. For the second model, it is assumed that the reform has been in effect since 1986, because that was the year in which all hospitals applied the new system. In the third model, the information about the implementation process is incorporated into a reform implementation index.

The reform implementation index for the introduction of the global budget system in France was established as follows: for the years before 1983, the value is 0. In 1983, parliament passed the reform, which may have caused some anticipatory effects in the field. For 1983 an index of 0.1 is therefore assumed. In 1984, all regional hospitals applied the new rules. For this situation, an index of 0.3 is assumed (bed capacity in regional hospitals was about 30\% of the total public hospital bed capacity in 1982; derived from [29], pp. 101). In 1985 the reform was spread over more hospitals, resulting in an index of 0.7 (a rough estimate of the 
Kroneman, M.W., Zee, J. van der. Health policy as a fuzzy concept: methodological problems encountered when evaluating health policy reforms in an international perspective. Health Policy: 1997, 40(2), 139-155

bed capacity relating to the new budgeting system). In 1986, all hospitals applied the new rules, resulting in an index of 1 .

Time series analysis has to be considered with caution since many other developments are capable of interference. In France, for instance, a bed reduction program was set up that came into effect at about the same time. It is possible that this development also influenced the average length of stay and the turnover rate in the same direction, in the same period of time. A variable for bed reduction is therefore also included to control for this effect. This variable consists of a 0 (zero) in the case of equal bed supply or bed expansion; in the case of bed reductions, this variable expresses the difference between the current year's supply and the supply in the previous year.

The data for average length of stay and turnover rate was obtained from the OECD health data files 1995: average length of stay per admission since 1961, and turnover rate since 1974. The last available year was 1993. The turnover rate refers to the number of different patients that occupied a bed in 1 year.

The results of the analyses are displayed in Table 1.

These analyses indicate that the hospital utilization indicators have not been affected for any of the models by the implementation of the new budgeting system. The introduction of the new budgeting system had no additional effect on the existing trends. There was no effect from the implementation of the reform on average length of stay, even when the process information was incorporated into the regression equation by means of the reform implementation index. Also, there was no significant effect on the turnover rate.

The temptation now arises to draw the conclusion that the budgeting policy has no effect on hospital utilization. This may however be premature. At least two other conclusions have to be considered. First, the chosen output parameters, average length of stay and turnover rate, may not be the correct parameters for measuring the effect of the policy. Since a major goal of this policy was to contain public expenditures on hospital care, the choice of a variable containing public expenditure level would seem logical. However, in the OECD health data files for 1995, data about public expenditures on inpatient care are insufficiently complete to permit time-series analysis to be carried out. Data are particularly deficient for the period of the policy reform; in the period from 1970 to 1985 public expenditure is presented only for every 5 years. The same analysis carried out on total inpatient expenditure, corrected for inflation, also failed to reveal any significant effects for each of the three models. The second alternative conclusion which could be drawn from the lack of effect of the policy is related to the first and concerns the type of data in the OECD health files. The OECD data contains aggregate variables at country level. Sometimes the aggregation is not suitable for the evaluation of the policy measure. In the French example, for instance, the budgeting reform is only applicable to the public hospital sector. However, the OECD health files only contain aggregate data including both public and private sector. The inclusion of the private sector still paid on a per diem basis (30\% of all hospital beds are in private hospitals) may disturb the effect of the policy measure.

Although the reform implementation index did not provide a better insight into the effect of the health policy reform than the other indexes, since none of them provided significant effects, the use of the reform implementation index gives a theoretical advantage. In the case of a gradual introduction, information about the period of time between initiation and full implementation is encapsulated in the index and better reflects reality than does the choice for a switch at the start or end of the implementation phase.

Summarizing, the advantages and drawbacks of each method of information gathering and analysis are listed in Table 2.

The first three methods provide insight into what has happened and can be used for descriptive purposes. The fourth method, the reform implementation index, facilitates statistical analysis. The best way to investigate health policy reforms is to use a combination of all these methods. The extent to which each method is used depends on the aim of the study, the detail of the information required and the budget available for the study; extensive 
Kroneman, M.W., Zee, J. van der. Health policy as a fuzzy concept: methodological problems encountered when evaluating health policy reforms in an international perspective. Health Policy: 1997, 40(2), 139-155

use of primary sources and expert consultation may lead to high translation and travel costs. It is, however, important to realize that none of the methods alone leads to a complete insight into the effect of reforms. The use of a reform implementation index is required when statistical analysis is used in studies into the effect of health care reforms, and in comparative research. The index cannot of course be formulated without first gathering information, using the first three methods.

\section{[FIGURE 3]}

\section{[TABLE 1]}

[TABLE 2]

\section{CONCLUSIONS AND DISCUSSION}

\subsection{Conclusions}

Fuzziness about the content of health policy reforms is not only a methodological problem, stemming from the need to summarize and select information in order to describe a health care system or reform in a succinct manner. The nature of many policy reforms also contributes to the fuzziness. Neither the commencement nor the exact phase of implementation are always clear; commencement may differ from the formal date of implementation. During the long time span from formal introduction to complete implementation, all kinds of other developments may interfere with the process (such as a change of government, setting out new policy lines).

Using primary sources and consulting experts, especially those familiar with the practicalities of the way rules are actually applied, helps to identify the type of 'fuzziness' relating to the policy process under study. When comparing health care reforms in different countries, or describing health care systems, it must be borne in mind that secondary sources are often very global in nature and this may lead to apparently contradictory information. A combination of different resources provides the best strategy for producing a reliable reconstruction of the reform process. Different sources provide different kinds of information. Secondary sources provide a global overview, primary sources provide insight into the original content of the reform and exact figures concerning norms, and so forth. Expert consultation is very useful for revealing exceptions and gradual implementation processes. Even the apparently harshest measures usually contain some exceptions, or other transition rules. These regulations are not always mentioned in the primary sources and secondary sources are often too global for this kind of information. To unearth any exceptions or transition rules, the best sources are health practitioners, such as hospital managers, or those responsible for paying the bills, such as insurance fund managers.

When evaluating reforms in a quantitative way, the reform implementation index is very useful, since it is constructed on the basis of knowledge of the implementation process. The usefulness of data at the national level (like the OECD health data files) for analysis of the effect of the introduction and implementation of specific health reforms is hampered by the (increasing) fuzziness of the policy process; the RI1 can facilitate the connection of health data with the introduction and implementation of reforms. If a national level is not the appropriate analysis level, the reform implementation index should be constructed at a regional level. 
Kroneman, M.W., Zee, J. van der. Health policy as a fuzzy concept: methodological problems encountered when evaluating health policy reforms in an international perspective. Health Policy: 1997, 40(2), 139-155

The aggregate nature of the OECD data may be troublesome in evaluating policy measures affecting only part of a sector. The appropriateness of data from the OECD health files should be considered critically. The emphasis on international comparability does not always make data suitable for studying intra national differences over time. The aggregations do not always fit the requirements of specific policy analysis.

\subsection{Discussion}

The extent and level (national or regional) for which different sources should be consulted depends on the aim and the subject of the study. In one and the same country, some regulations may be implemented at a national level and other responsibilities may be delegated to the region. In Sweden, the waiting time guarantee operates at national level while the hospital financing systems operates regionally. The detail to which the information has to be gathered also depends on the aim of the study. A quantitative analysis of a reform requires a detailed insight in the implementation process. This provides information to reconstruct the Reform Implementation Index and ensures a correct connection of data to implementation phases. Most of the examples in this paper stem from pluralistic social security based health care systems, where responsibility is spread over different actors and neither they nor the Ministry of Health is all powerful. Do the same principles apply to centrally organized National Health Services? To a certain extent they do, indeed. According to Klein ([30] the 1991 NHS reforms in the UK provides an example; one of the innovations was the introduction of 'fundholding' general practitioners; this innovation is still open to applicants and has now reached between 40 and 50\% of British GPs. The government had the power (and used it) to introduce these reforms more or less overnight, but it nevertheless took time for the actual implementation.

Is the Reform Implementation Index really an improvement over an ordinary 'time-lag' function in the model? It is a sort of time lag parameter, although not a mechanical one constructed to make the equation fit better. The RI1 should be constructed and applied on the basis of information about the actual progress of the policy process.

Is it, given the intrinsic 'fuzziness' of policy making, permissible to connect policy reforms to data in the OECD-files in comparative studies? The answer to this question must remain ambiguous. It is true that the quality of OECD data is steadily improving and that it provides an extremely cost effective way of comparing the performance of health care systems that could not otherwise be obtained. So, if a naive and discrete concept of health policy could be replaced by a more gradual and 'fuzzy' idea, both domains are capable of being matched.

\section{ACKNOWLEDGEMENTS}

The authors are grateful to their informants from 'Gyógyinfók' (Information Centre of the Ministry of Health, Hungary) and the Hungarian National Sickness Fund for providing information about the Hungarian hospital sector. The authors also thank Dr D. Quaghebeur of the Belgium 'Landsbond van Christelijke Mutualiteiten' (an umbrella organization for the health insurance associations) for putting the primary sources (legal texts) for Belgium at our disposal.

\section{REFERENCES}

[I] Liischen, G., Cockerham, W., Zee, J.van der, Stevens, F., Diederiks, J., Ferrando, M.G. et al., Health Systems in the European Union. Diversity, Convergence, and Integration, Oldenbourg, München, 1995.

[2] Saltman, R.B., A conceptual overview of recent health care reforms, European Journal of Public Health, 4 (1994) 287-293. 
Kroneman, M.W., Zee, J. van der. Health policy as a fuzzy concept: methodological problems encountered when evaluating health policy reforms in an international perspective. Health Policy: 1997, 40(2), 139-155

[3] van Kemenade, Y.W. and de Jong, B., Gezondheidszorgstelsels in Europa (Health care systems in Europe), Medisch Contact, 48 (1993) 114991154.

[4] OECD, The reform of health care. A comparative analysis of seven OECD countries, Health Policy Studies no. 2, Organization for Economic Co-Operation and Development, Paris, 1992.

[5] OECD, The reform of health care systems: a review of seventeen OECD countries, Organization for Economic Co-Operation and Development, Paris, 1994.

[6] OECD, Financing and delivering health care, A comparative analysis of OECD countries, Social Policy Studies No. 4, Organization for Economic Co-Operation and Development, Paris, 1987.

[7] OECD, OECD health systems, facts and trends 1960-1991, Health Policy Studies no. 3, Organization for Economic Co-Operation and Development, Paris, France, 1993.

[8] Scheffler, R.M., Containing health care costs: International comparisons. In: X. Gonzales Mestre and J.J. Escoda Areste (Eds.), Politiques de contencio de costos sanitaris, Ficosser-projecte IV, Barcelona, 1994, pp. 11-20.

[9] Godt, P.J., Confrontation, consent and corporatism: state strategies and the medical profession in France, Great Britain, and West Germany, Journal of Health Politics, Policy and Law, 12 (1987) 4599480.

[IO] Wiley, M.M., Hospital financing reform and case-mix measurement: an international review, Health Care Financing Review, 13 (1992) 119-133.

[1 1] Rosa, J.J. and Launois, R., France. Advances in health economics and health services research, In: J.J. Rosa, R.M. Scheffler and R.F. Rossiter (Eds.), Comparative health systems: the future of national health care systems and economic analysis, JAI Press, Greenwich/Connecticut, 1990,

[12] Beske, F., Expenditures and attempts of cost containment in the statutory health insurance system of the Federal Republic of Germany. In: G. McLachlan and A. Maynard (Eds.), The public/private mix for health. The relevance and effects of change, The Nuffield Provincial Hospitals Trust, London, 1982, pp. 233-261.

[13] Paulson, E.M., Hospital financing in Sweden. In: M. Wiley, M.A. Laschober and H. Gelband (Eds.), Hospital financing in seven countries, U.S. Government Printing Office, Washington, DC, 1995, pp. 121-134.

[14] Sobczak, P.M., Fottler, M.D. and Chastagner, D., Managing retrenchment in French public hospitals: philosophical and regulatory constraints, International Journal of Health Planning and Management, 3 (1988) 19-34.

[15] Vreugdenhil. J.C. and de Bruine, M., Gezondheidszorg in Europa (Health care in Europe), Rotterdam, 1992.

[16] Krukemeyer, H., Vergleichende Systemanalyse des Krankenhauswesens in den OECDLandem (Comparative system analysis of hospital organisation in the OECD countries), Verlag H.M. Hauschild GMBH, Bremen, 1985.

[17] Aiach, P. and Delanoe, J.Y., La politique economique du gouvernement socialiste en matière de santé: Bilan de cinq annees de pouvoir en France, 1981-1986 (Economic policy of the socialist government concerning health: Results of a five year period of office in France, 1981-1986), Social Science and Medicine, 28(6) (1989) 539-550.

[18] Glaser, W.A., Health insurance in practice; International variations in financing benefits, and problems, Jossey-Bass, San Francisco, 1991.

[19] Meyer-Lie, A., A comparative health services study (Finland, Hungary, Italy, The Netherlands, Sweden), WHO, Regional Office for Europe, Copenhagen, 1986.

[20] Groenewegen, P.P., The shadow of the future: institutional change in health care, Health Affairs, 13(5) (1994) 137-148.

[21] Hanning, M., Maximum waiting-time guarantee-an attempt to reduce waiting lists in Sweden, Health Policy, 36 (1996) 17-35.

[22] Sachverstandigenrat fur die Konzertierte Aktion im Gesundheitswesen,, Gesundheitsversorgung und Krankenversicherung 2000. Eigenverantwortung, Subsidiaritlt und Solidaritat bei sich Inderenden Rahmenbedingungen (Health care and health insurance 2000. Responsibility, subsidiarity and solidarity under changing conditions), Nomos Verlagsgesellschaft, Baden-Baden, 1994.

[23] Graig, L.A., Health of nations; an international perspective on U.S. health care reform, 2nd edn, Congressional Quarterly, Washington, 1993. 
Kroneman, M.W., Zee, J. van der. Health policy as a fuzzy concept: methodological problems encountered when evaluating health policy reforms in an international perspective. Health Policy: 1997, 40(2), 139-155

[24] Mattheis, R., Macro-allocation in health care in the Federal Republic of Germany. In: H.M. Sass and R.U. Massey (Eds.), Health care systems, Kluwer, Dordrecht, 1988, pp. 201-212.

[25] Made, J.H., Janssen, R.T.J.M. and Lieverdink, H.J., Kostenbeheersing door overleg: budgettering van medisch-specialisten in Nederland en Duitsland (Cost containment by consultation: budgeting medical specialists in the Netherlands and Germany). In: I.M.A.M. Propper and M. Herweijer (Eds.), Effecten van plannen en convenanten (Effects of plans and covenants), Kluwer, Dordrecht, 1992, pp. 235-261.

[26] Beeckmans, J., Het Belgisch ziekenhuis (Hospitals in Belgium), De Tijdstroom, Lochem/Gent, 1986.

[27] Cannoodt, L., Ontwikkelingen in de ziekenhuisprogrammatie (Developments in hospital planning), Verpleegkundigen en Gemeenschapszorg, 3 (1987) 119- 128.

[28] van den Heuvel, R. and Sacrez, A., Cost containment in health insurance; the case of Belgium. In: G. McLachlan and A. Maynard (Eds.), The Public/Private mix for Health. The Relevance and Effects of hange, The Nuffield Provincial Hospitals Trust, London, 1982, pp. 2077232.

[29] Bonamour, P., Introduction to the French system. In: F. Beske, L. Delesie, F. Rutten and H. Zoellner (Eds.), Hospital Financing Systems, Kiel, 1987, pp. 94-103.

[30] Klein, R., Big bang health care reform-Does it work?: The case of Britain's 1991 National Health Service reforms, The Milbank Quarterly, 73(3) (1995) 299-337.

\section{TABLES AND FIGURES}

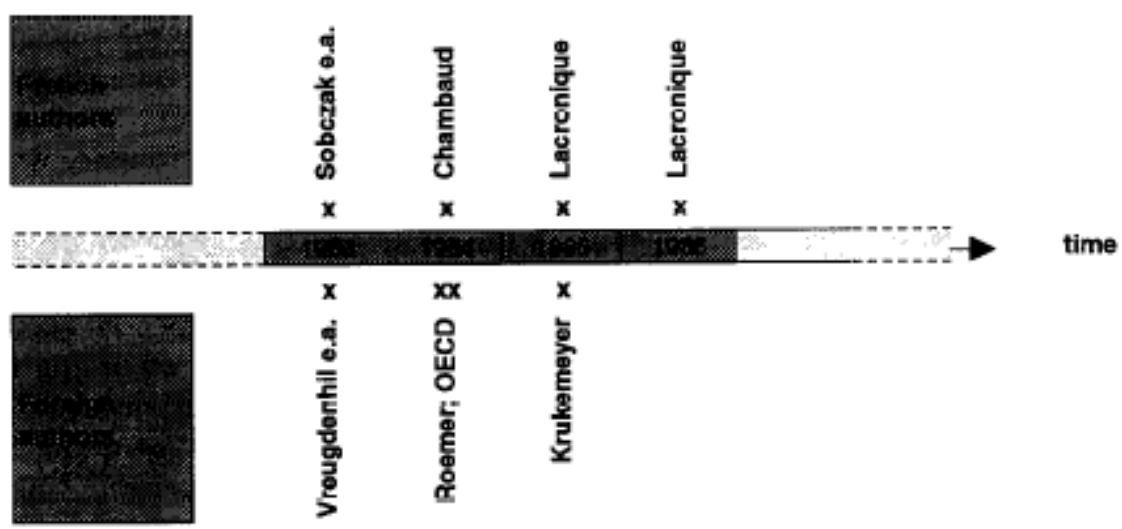

Fig. 1. An overview of years of introduction of the global budgeting system in France mentioned by different sources. 
Kroneman, M.W., Zee, J. van der. Health policy as a fuzzy concept: methodological problems encountered when evaluating health policy reforms in an international perspective. Health Policy: 1997, 40(2), 139-155
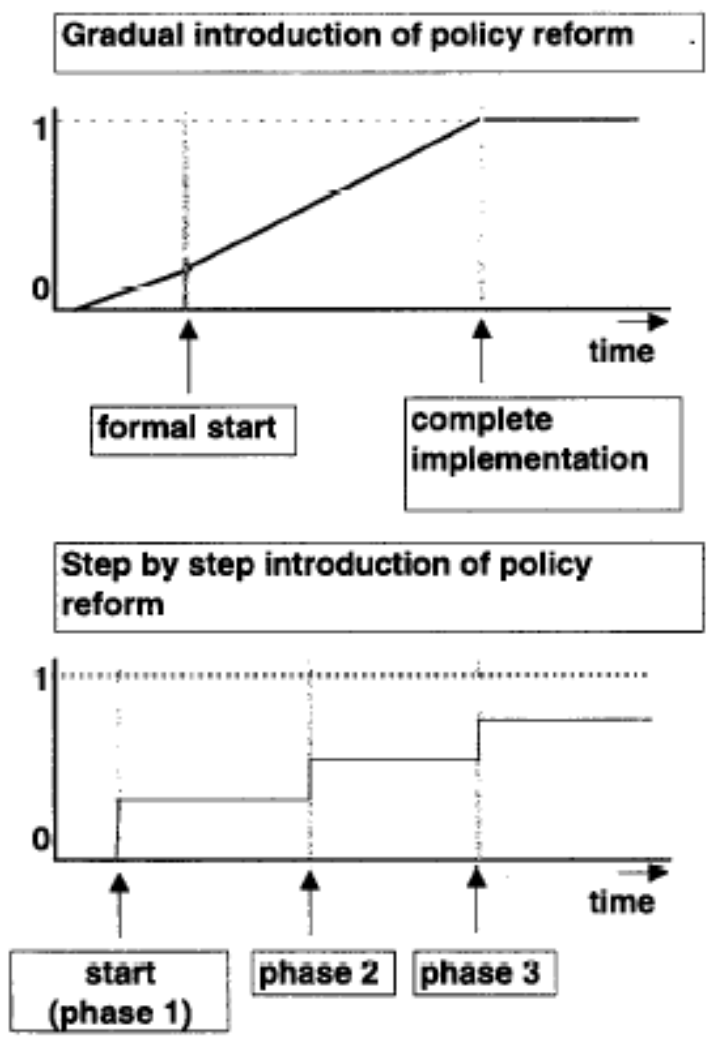

Fig. 2. Two examples of a shape that a 'reform implementation index' can take through time.

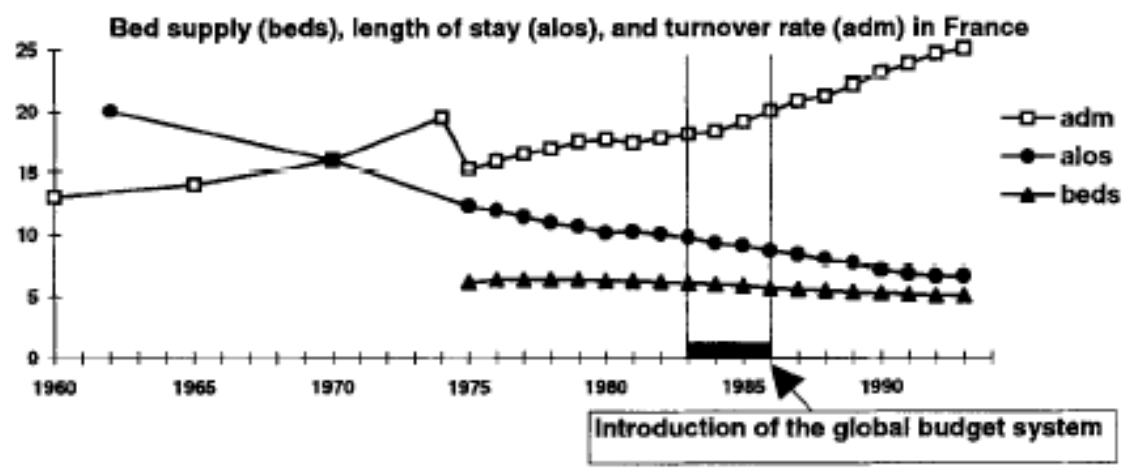

Fig. 3. Hospital production and supply in France (1961-1993). 
Kroneman, M.W., Zee, J. van der. Health policy as a fuzzy concept: methodological problems encountered when evaluating health policy reforms in an international perspective. Health Policy: 1997, 40(2), 139-155

Table 1

The influence of the introduction of the global budget system on hospital utilization, controlling for bed reductions and time effects (by means of regreesion analysis; B-statistics and significance of t-statistics are presented) $)^{\mathrm{a}}$

\begin{tabular}{|c|c|c|c|}
\hline Variable & Mudel $1^{b}$ & Mudel $2^{b}$ & Mudel 3 \\
\hline \multicolumn{4}{|c|}{ Dependent variable: average length of stay $(n-33)$} \\
\hline Years & $\begin{array}{c}-0.32 \\
(0.00)\end{array}$ & $\begin{array}{c}-0.30 \\
(0.00)\end{array}$ & $\begin{array}{r}-0.30 \\
(0.00)\end{array}$ \\
\hline Dedreduc & $\begin{array}{c}-0.71 \\
(0.78)\end{array}$ & $\begin{array}{r}-1.63 \\
(0.54)\end{array}$ & $\begin{array}{r}-1.10 \\
(0.66)\end{array}$ \\
\hline Reform & $\begin{array}{r}0.03 \\
(0.98)\end{array}$ & $\begin{array}{c}-0.70 \\
(0.47)\end{array}$ & $\begin{array}{r}-0.74 \\
(0.59)\end{array}$ \\
\hline Constant & 652.63 & 613.46 & 603.22 \\
\hline $\mathrm{Rho}^{3)}$ & 0.70 & 0.68 & 0.69 \\
\hline Adjusted $\mathbf{R}^{2}$ : & 0.87 & 0.88 & 0.88 \\
\hline \multicolumn{4}{|c|}{ Dependent variable: turnover rate, $(n=22)$} \\
\hline Years & $\begin{array}{c}0.38 \\
(0.01)\end{array}$ & $\begin{array}{c}0.31 \\
(0.01)\end{array}$ & $\begin{array}{c}0.25 \\
(0.15)\end{array}$ \\
\hline Bedreduc & $\begin{array}{c}0.30 \\
(0.93)\end{array}$ & $\begin{array}{c}2.69 \\
(0.48)\end{array}$ & $\begin{array}{r}1.36 \\
(0.69)\end{array}$ \\
\hline Reform & $\begin{array}{c}0.00 \\
(0.99)\end{array}$ & $\begin{array}{c}1.88 \\
(0.18)\end{array}$ & $\begin{array}{r}2.36 \\
(0.16)\end{array}$ \\
\hline Constant & -727.70 & -586.45 & -469.89 \\
\hline Rho $^{c}$ & 0.70 & 0.53 & 0.62 \\
\hline Adjusted $\mathrm{R}^{\mathrm{b}}$ : & 0.82 & 0.86 & 0.85 \\
\hline
\end{tabular}

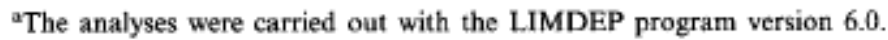

'Model 1: the reform has been in effect since its formal introduction in 1983 (Reform switches from zero to one in 1983); Model 2. the reform has heen in effect since all (public) hospitals first applied the new budgeting system in 1986 (Reform switches from zero to one in 1986); Model 3: The reform has been introduced gradually, the process is encapsulated in a reform implementation index, which gradually changes from zero to one between 1983 and 1986.

${ }^{3}$ Rho indicates the correction for auto-correlation of the residuals according to the Prais-Winston method. 
Kroneman, M.W., Zee, J. van der. Health policy as a fuzzy concept: methodological problems encountered when evaluating health policy reforms in an international perspective. Health Policy: 1997, 40(2), 139-155

Table 2

Advantages and drawbacks of research methods into health policy changes

\begin{tabular}{|c|c|c|}
\hline Method & Advantages & Drawbacks \\
\hline $\begin{array}{c}\text { Secondary } \\
\text { sources }\end{array}$ & $\begin{array}{l}\text { Overview of reform } \\
\text { Inconsistencies and lack of clarity are } \\
\text { revealed, facilitating targeted further } \\
\text { investigations }\end{array}$ & $\begin{array}{l}\text { Sometimes too global to give real } \\
\text { insight } \\
\text { The global nature of the information } \\
\text { may lead to apparent contradictions } \\
\text { The interpretation of the author may } \\
\text { lead to biased information }\end{array}$ \\
\hline Primary sources & $\begin{array}{l}\text { Initial intention of reform is revealed } \\
\text { Exact contents of norms and rules } \\
\text { can be found }\end{array}$ & $\begin{array}{l}\text { Possible high translations costs } \\
\text { Uncertainty about real implementation }\end{array}$ \\
\hline $\begin{array}{l}\text { Expert } \\
\text { consultation }\end{array}$ & $\begin{array}{l}\text { Unintended effects may be revealed } \\
\text { The actual course of implementation } \\
\text { and implementation problems are } \\
\text { discovered }\end{array}$ & $\begin{array}{l}\text { Experts may give biased information, } \\
\text { depending on their position } \\
\text { No exact information about } \\
\text { implementation dates (because } \\
\text { investigations are retrospective) }\end{array}$ \\
\hline $\begin{array}{l}\text { Reform } \\
\text { implementation } \\
\text { index }\end{array}$ & $\begin{array}{l}\text { Information about the inplementation } \\
\text { course can be included in the } \\
\text { statistical analysis }\end{array}$ & $\begin{array}{l}\text { Qualitative intormation has to be } \\
\text { transformed into numerical values, } \\
\text { possibly leading to information loss }\end{array}$ \\
\hline
\end{tabular}

